San Jose State University

SJSU ScholarWorks

Master's Theses

Master's Theses and Graduate Research

1994

\title{
A relationship study of the percentage of high-level objectives and the percentage of related exam questions in an associate degree nursing program
}

Susan Marie Wetzel

San Jose State University

Follow this and additional works at: https://scholarworks.sjsu.edu/etd_theses

\section{Recommended Citation}

Wetzel, Susan Marie, "A relationship study of the percentage of high-level objectives and the percentage of related exam questions in an associate degree nursing program" (1994). Master's Theses. 966. DOI: https://doi.org/10.31979/etd.kvkr-s4yv https://scholarworks.sjsu.edu/etd_theses/966

This Thesis is brought to you for free and open access by the Master's Theses and Graduate Research at SJSU ScholarWorks. It has been accepted for inclusion in Master's Theses by an authorized administrator of SJSU ScholarWorks. For more information, please contact scholarworks@sjsu.edu. 


\section{INFORMATION TO USERS}

This manuscript has been reproduced from the microfilm master. UMI films the text directly from the original or copy submitted. Thus, some thesis and dissertation copies are in typewriter face, while others may be from any type of computer printer.

The quality of this reproduction is dependent upon the quality of the copy submitted. Broken or indistinct print, colored or poor quality illustrations and photographs, print bleedthrough, substandard margins, and improper alignment can adversely affect reproduction.

In the unlikely event that the author did not send UMI a complete manuscript and there are missing pages, these will be noted. Also, if unauthorized copyright material had to be removed, a note will indicate the deletion.

Oversize materials (e.g., maps, drawings, charts) are reproduced by sectioning the original, beginning at the upper left-hand corner and contiming from left to right in equal sections with small overlaps. Each original is also photographed in one exposure and is included in reduced form at the back of the book.

Photographs included in the original manuscript have been reproduced xerographically in this copy. Higher quality $6^{n} \times 9^{n}$ black and white photographic prints are available for any photographs or illustrations appearing in this copy for an additional charge. Contact UMI directly to order.

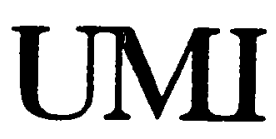

A Bell \& Howell information Company

300 North Zeeb Road. Ann Arbor. MI 48106-1346 USA

313:761-4700 800:521-0600 

A Relationship Study of the Percentage of High-Level Objectives and the Percentage of Related Exam Questions in an Associate Degree Nursing Program

\author{
A Thesis \\ Presented to \\ The Faculty of the School of Nursing \\ San Jose State University \\ In Partial Fulfillment \\ of the Requirements for the Degree \\ Master of Science
}

by

Susan Marie Wetzel

December, 1994 
UMI Number : 1361226

Copyright 1994 by Wetzel, Susan Marie All rights reserved.

UMI Microform 1361226

Copyright 1995, by UMI Company. All rights reserved.

This microform edition is protected against unauthorized copying under Title 17, United States Code.

\section{UMI}

300 North Zeeb Road

Ann Arbor, MI 48103 
Copyright 1994

Susan Marie Wetzel

ALL RIGHTS RESERVED 
APPROVED FOR THE SCHOOL OF NURSING

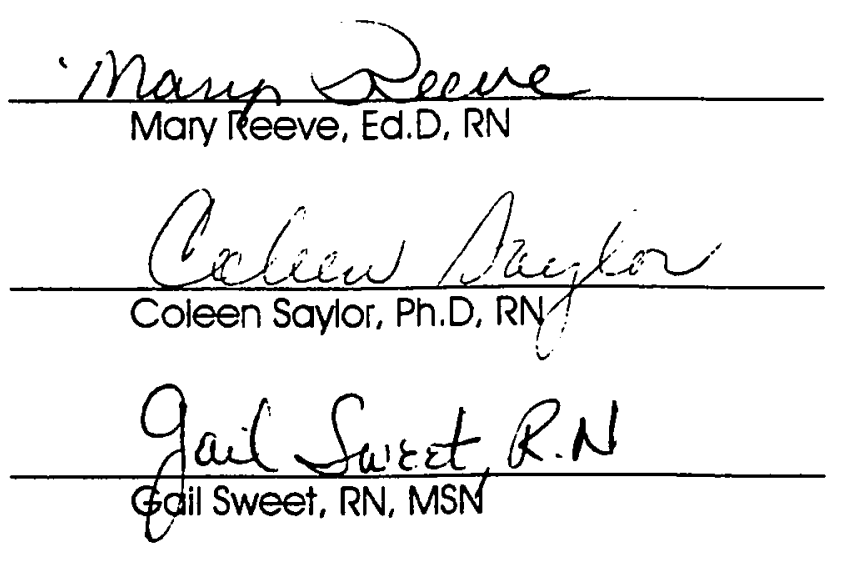

APPROVED FOR THE UNIVERSITY

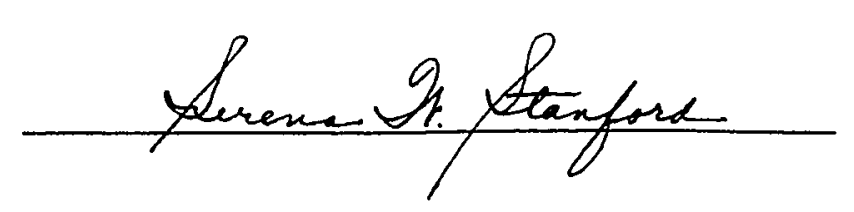




\begin{abstract}
A Relationship Study of the Percentage of High-Level Objectives and the Percentage of Related Exam Questions in an Associate Degree Nursing Program

by Susan M. Wetzel
\end{abstract}

\begin{abstract}
The purpose of this study was to gather data on an associate degree nursing program to determine if critical thinking was encouraged and evaluated by the use of higher level objectives. This study investigated whether there was a relationship between the frequency of objectives that could be met with higherlevel thinking skills used in critical thinking and the frequency of exam questions that related to these objectives. Spearman's correlation coefficient was used on the ordinal data. The results indicated that there was no statistically significant relationship (is=.09) between a percentage of higher level objectives and the percentage of related examination questions in an associate degree program. Review of the data suggests that this nursing curriculum did not utilize higherlevel objectives in a prevalent or progressive manner. Questions for future research are also generated from the data.
\end{abstract}




\section{ACKNOWLEDGMENTS}

I would like to extend my sincere appreciation to my dearest family members. My sister Linda, her family, and my son Eric for their patience and time together. To my husband who provided dedicated, sincere and relentless support throughout this challenging endeavor.

In memory of Kimberly Dawn, my friend and partner in nursing. 


\section{TABLE OF CONTENTS}

Page

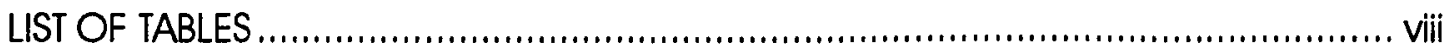

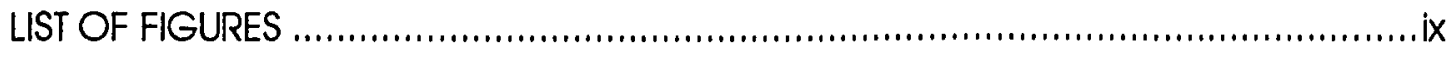

Chapter

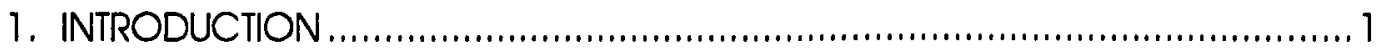

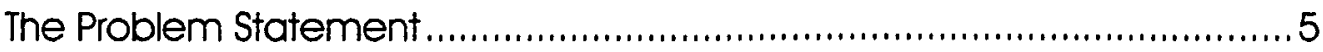

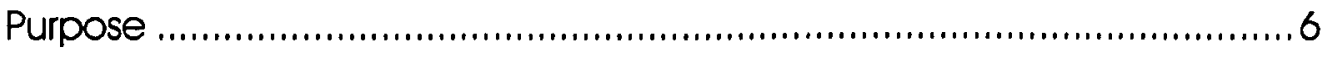

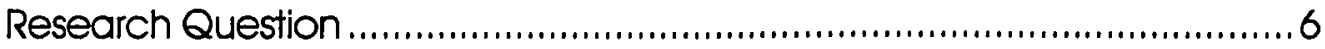

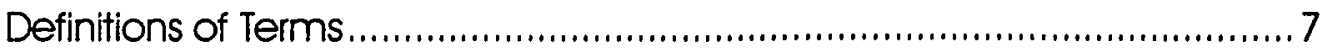

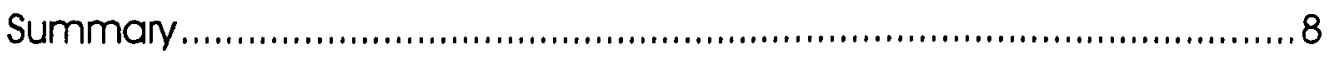

2. CONCEPTUAL FRAMEWORK AND REVIEW OF RELATED LITERATURE ...............9

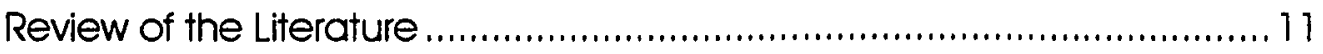

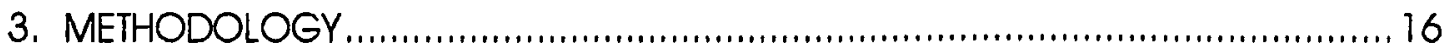

Subjects and Data Collection ......................................................... 16

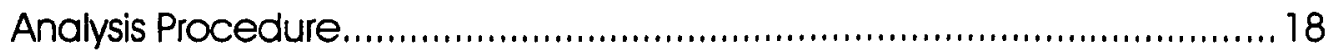

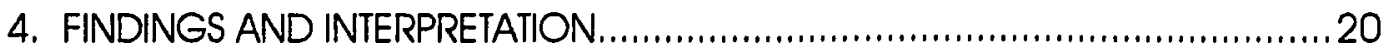

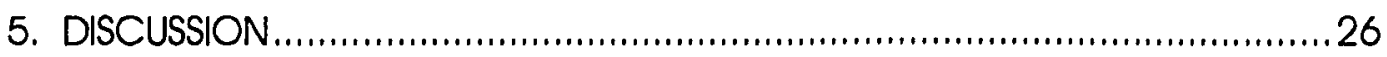

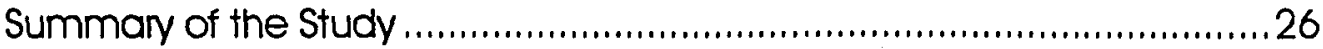

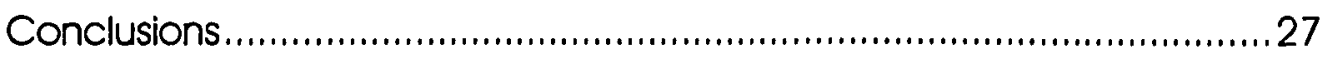

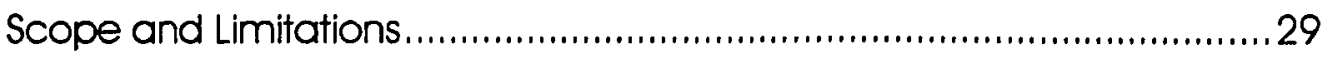

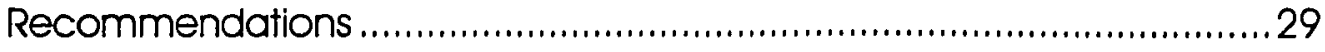

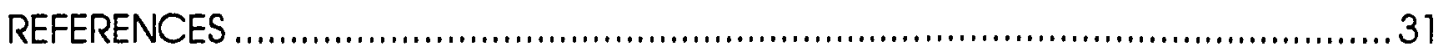




\section{APPENDIXES}

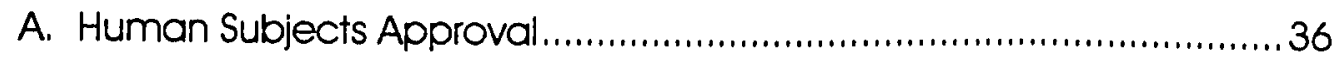

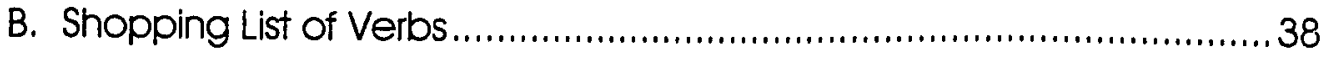

C. Spearman's Correlation Coefficient.................................................. 40 


\section{LIST OF TABLES}

Table

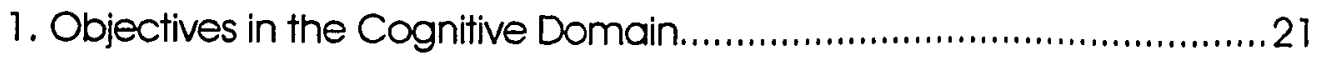

2. Frequency and Percentage of Objectives in the Cognitive Domain ...22

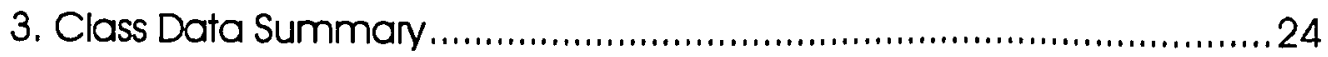


Figure

LIST OF FIGURES

1. Percentage of Higher-Level Objectives and the Percentage of Related

Examination Questions ..........................................................23 


\section{Chapter 1}

\section{INTRODUCTION}

Nurse educators have attempted to develop critical thinking abilities in students since the early 1930s. A historical analysis of nursing education concluded that the acquisitions of cultural knowledge, the possession of a strong science background, and the development of critical thinking skills are the goals of nursing education (Hanson, 1991). Critical thinking is considered an important skill in the future of professional nursing practice due to the rapidly changing health care environment and technology. Many studies agree that nurses are required to synthesize multiple forms of knowledge, which is one aspect of critical thinking, to provide safe care to their patient (Kintgen-Andrews, 1991; Kramer, 1993: Tschikota, 1993). There have been mixed results regarding the impact of nursing education on critical thinking. For example, Kintgen-Andrews found the critical thinking abilities of nursing students were not affected by the educational program to which they were exposed. However, Gross, Takazawa, and Rose (1987) found that nursing students' ability to think critically was significantly improved by their educational program.

Nursing faculty in clinical settings have expressed concern over the apparent inability of some students to apply knowledge from reading, lectures, and seminars to patient care situations. Faculty in lecture courses express similar concern over students' difficulty with exam questions that require them to apply course content to hypothetical clinical situations. The difficulty that students experience in applying or transferring content might at least partially be the consequence of the failure to provide students with opportunities to learn the 
cognitive skills involved in critical thinking (Bowers \& McCarthy, 1993). Facilitating the development of critical thinking required to deal with variations in clinical settings demands careful attention to the way teaching strategies and course assignments are constructed, sequenced, and evaluated (Bowers \& McCarthy). Exams may need to be rewritten to shift the focus from retention of the facts to encouraging critical thinking. One way of doing this is for instructors to write highlevel objectives that would encourage the students to use critical thinking skills in meeting these objectives. Test questions should then reflect the content from the objectives. Educational accountability requires examination and justification of curricula that will promote critical thinking skills (White, Beardslee, Peters \& Supplies, 1990).

Critical thinking is difficult to define and measure. The traditional ideas of critical thinking are defined as a composite of attitudes, knowledge, and skills (Berger, 1984). The definitions of critical thinking range from an activity to develop broad understanding, to reflective thinking that is focused upon deciding what to believe (Kingten-Andrews, 1991; Kramer, 1993). All the definitions address higher-level analytical skills such as synthesis, analysis, and evaluation. However, there is still considerable discussion of the definition of critical thinking. Yinger (1980) defines critical thinking as the cognitive activity associated with the evaluation of thought processes. Jones and Brown (1991) find critical thinking to be operationalized as a rational linear process and a function of deductive thinking. Brooks and Shepherd (1990) define critical thinking as an attitude of inquiry. This study used an eclectic definition by Kramer (1993) "...critical thinking is generally regarded as a practical activity that helps 
the learner develop broad understanding of situations...the learner explores some situations, questions, or problem to reach a reasoned conclusion that can be convincingly justified" (p. 406).

The traditional concept of critical thinking, defined as a composite of attitudes, knowledge, and skills, is operationalized as the score on the WatsonGlaser Critical Thinking Appraisal instrument in most of the published research on critical thinking (Pless \& Clayton, 1993). Watson and Glaser developed the following list of abilities that comprise the critical thinking score:

1. The ability to define a problem

2. The ability to select pertinent information for the solution of a problem

3. The ability to recognize stated and unstated assumptions

4. The ability to formulate and select relevant and promising hypotheses and

5. The ability to draw conclusions validly and to judge the validity of inference.

(Berger, 1984, p. 307)

Because of the practice focus of nursing, the definition of critical thinking by Watson and Glaser appears to be the one most widely used in nursing (Miller \& Malcolm, 1990). All the definitions use higher-level analytical skills that lead to the notion that critical thinking skills can be developed in the educational setting. Skills can be acquired according to learning theories such as behaviorism and cognitivism. The cognitive learning theory, for example, is concerned with a student's acquisition of skills relating to the organization of information 
processing, problem solving, and metacognition used in critical thinking (Le Francois, 1994).

A learning objective is a statement that identifies what the learner is to accomplish. Course objectives may be written to encourage the student to use higher-level analytical skills such as critical thinking. Objectives provide a framework for devising ways to evaluate student learning and guide the design of relevant testing items and procedures (Kemp, 1985). Objectives are to have two essential parts, an action verb followed by the subject content reference. The selection of the appropriate action verb will assist in recognizing the high intellectual level objectives. Bloom's taxonomy organizes these action verbs (Bloom. 1956). Course objectives of a nursing program could encourage critical thinking to prepare graduates to function in the modern health care setting by selecting verbs which reflect the higher cognitive levels in Bloom's taxonomy.

Bloom's taxonomy is in three major parts, the cognitive, the affective, and the psychomotor. The first domain, cognitive, will be addressed in this study. "The cognitive domain includes those objectives which deal with the recall or recognition of knowledge and the development of intellectual abilities and skills" (Bloom, 1956, p.7). There is a hierarchical order to the classes of objectives. In the cognitive domain, the order of classes is as follows: 1.00 Knowledge 2.00 Comprehension, 3.00 Application, 4.00 Analysis, 5.00 Syntheses, 6.00 Evaluation. The order is arranged from simple to complex. Bloom (1956) states that the "intellectual abilities and skills" known as critical thinking, come in the categories of application, analysis, synthesis and evaluation. 
The Problem Statement

The American Nurse's Association and the National League for Nursing require education only at the baccalaureate level to prepare nurses to perform high level cognitive tasks in the every day care of their patients (McNelly-Greene, 1991). In the National League for Nursing accreditation process of baccalaureate programs, evidence of critical thinking is a required criterion for the programs under review. This criterion requires that the curriculum emphasize the development and measurement of critical thinking (National League for Nursing, 1992). Associate degree programs are not required to include critical thinking criteria in their curriculum (National League for Nursing, 1993). On the bases of these standards, baccalaureate education rather than associate degree education is mandated to the development of critical thinking and independent decision-making. However, studies attempting to determine if differences exist in critical thinking of ADN and BSN students have conflicting evidence (Lynch, 1988; McNeely-Greene, 1991).

With the increased technology in today's medical arena, nursing education at all levels should be required to encourage critical thinking. It is important to examine the educational experiences of the associate degree graduate, as most nurses are prepared for practice at this level, to document what they are learning (McNeely-Greene, 1991). Fifty-seven percent of the total number of basic registered nurse (R.N.) programs are associate degree programs (National League of Nursing Division of Research, 1993). Historically, total enrollment in associate programs has been higher than baccaloureate programs. In 1993, 102.128 students enrolled in baccalaureate programs, 
132,603 students enrolled in associate degree programs. Graduates from associate degree programs are at an all time high of 52,896 (National League of Nursing Division of Research). The number of associate degree graduates suggest that they are responsible for the majority of nursing care in the United States today (McNeely-Greene, 1991). Nurse educators must be concerned with the development of critical thinking skills to help all students function in the role of today's nurse.

\section{Purpose}

The purpose of this study was to gather data on an associate degree nursing program to determine if critical thinking was encouraged and evaluated by the use of higher level objectives. This study attempted to see if there was a relationship between the percentage of objectives that can be met with higherlevel thinking skills used in critical thinking and the percentage of exam questions that related to these objectives. The percentage of higher-level objectives was examined within the nursing program, and the percentage of related exam questions on examinations was evaluated to see if there was a correlation between these two variables. The broad goal of this study was to obtain base line data for the encouragement of critical thinking in the education of registered nurses.

Research Question

Is there a relationship between the percentage of higher-level educational objectives and the percentage of related examination questions in an associate degree nursing program? 
Definitions of Terms

For the purpose of this study, the following definitions apply:

1. Higher-level objective is a learning objective that encourages critical thinking (Bloom, 1956). Objectives have two essential parts, an action verb followed by the subject content reference. The selection of the appropriate action verb will assist in recognizing the higher-level objectives. Bloom's taxonomy will be used to organize the action verbs. Bloom labels the lowest action verb level as knowledge and increases in more intellectual levels to comprehension, application, analysis, synthesis and evaluation (Kemp, 1985). Higher-level objectives for this study will be identified using action verbs from application, analysis, synthesis, or evaluation.

2. Critical thinking is operationalized in this study using the definition from Kramer (1993): "critical thinking is generally regarded as a practical activity that helps the learner develop broad understanding of situations...the learner explores some situations, question, or problem to reach a reasoned conclusion that can be convincingly justified " p. 406. In addition, "critical thinking outcomes should reflect students skills in reasoning, analysis, research, or decision making relevant to the discipline of nursing" (National League for Nursing, 1992, p.6).

3. Related exam question is a question on an exam that requires the student to have studied all or part of the material required from a higher-level objective to answer the question correctly. 


\section{Summary}

The American Nurses Association and the National League for Nurses maintain that there are two separate levels of nursing functions, the "professional" and the "technical" nurse (McNeeley-Greene, 1991). These organizations maintain that the professional nurse can carry out complex functions and should be a university graquate. In contrast, the technical nurse is responsible for the more mechanical and concrete tasks of nursing and is a graduate from an associate degree program. If education follows these recommendations, then most of today's nurses would not be prepared to provide complex care. In the increasingly complex health care setting, critical thinking is essential to nursing practice at all levels. This study examined an associate degree program to see evidence of educational objectives that promoted higher-level cognitive skills necessary in critical thinking through comparative assessment between objectives and exam questions. This study examined one portion of the associate degree curriculum to help document the level of objectives and their evaluation. 


\section{Chapter 2}

CONCEPTUAL FRAMEWORK AND REVIEW OF RELATED LITERATURE

The conceptual framework for this study is derived from the works of Kramer (1993) and Bloom (1956). Kramer uses critical thinking in the process of clarifying concepts to aid the development of nursing theory. Concept clarification both requires and extends critical thinking. Kramer includes four components of critical thinking: (a) identifying and challenging assumptions, (b) becoming aware of the importance of context in creating meaning, (c) imagining and exploring alternatives, and (d) cultivating a reflective skepticism. Kramer defines critical thinking as "a practical activity that helps the learner develop broad understandings of situations...the learner explores some situations, questions or problems to reach a reasoned conclusion that can be convincingly justified" (p. 406). Kramer believes critical thinking requires both attitudes of inquisitiveness as well as information in the nursing practice, In addition, Kramer recognizes the importance of critical thinking in education and encouraged nurse educators to acquire critical thinking skill through further education if they are going to require their students to become critical thinkers.

The idea to use Bloom's taxonomy for this study originated with McNeelyGreene's work (1991). The Taxonomy of Educational Objectives is one of the more influential works in education today (Paul, 1985). Teachers generally accept the categories of the taxonomy as a teaching principle (Paul). Critical thinking is equated with Bloom's higher-order objectives in Bloom's (1956) cognitive domain: 
It is expected that when the students encounters a new problem or situation, he will select an appropriate technique for attacking it and will bring to bear the necessary information, both facts and principles. This has been labeled 'critical thinking' by some... in the taxonomy we have used the term 'intellectual abilities and skills' (p.37).

Bloom (1956) defines these abilities and skills as those which the individual uses to find appropriate information and techniques from his previous experience to interpret new problems and situations. This requires analysis of background information and the ability to discern relationships between new and old experiences. Bloom recognizes that unless the individual can do his own problem solving, he cannot maintain his integrity as an independent person.

The intent of the taxonomy is to provide a classification of the goals of the educational system with a set of standard classifications. It can also help gain a perspective on the emphasis given to certain behaviors by categorizing the objectives (Bloom, 1956). "The taxonomy is designed to be a classification of the student behaviors which represent the intended outcomes of the educational process" (p.12).

The works of Kramer (1993) and Bloom (1956) form the framework for this study. Kramer brings critical thinking to nursing in a well-defined manner by emphasizing the importance of critical thinking in clarifying concepts in nursing theory. Bloom helps to give standard classifications which educators can use to develop objectives, teaching strategies, and evaluation tools to emphasis high- 
level concepts used in critical thinking. Both concepts are important to the theories and the practice of nursing education.

Review of the Literature

There is a wide body of knowledge on critical thinking in the field of education. This literature review includes studies that indicate that there is a lack of consensus on the definition of critical thinking. There is also conflicting evidence of the impact nursing education has on critical thinking abilities in students. In addition, higher-level objectives are equated with critical thinking with the use of Bloom's taxonomy,

The justification for the encouragement of critical thinking and the conceptual framework for this study, is based on works by philosophers of education. According to their view, critical thinking is an indispensable part of education. Being able to think critically is a necessary condition for being educated (Norris, 1989). According to this reasoning, students have a moral right to question and challenge what is being taught (Siegel, 1980). Critical thinking is used in an interdisciplinary manner and allows the presentation of different points of view. Critical thinking recognizes the importance of higherlevel thinking in which learning occurs as the result of progressing toward a conclusion rather than accepting someone else's conclusion (Jones \& Brown, 1991).

Yinger (1980) sees critical thinking as operating with a creative and critical aspect. The creative aspect permits the production of ideas and alternatives and the critical aspect enables the testing and evaluation of the outcomes of critical thinking (Gross, Takazawa, \& Rose, 1987). Critical thinking theory suggests 
that critical thinking is the application of principles where information is evaluated in a process of conjecture, perspective, and background knowledge (Jones \& Brown, 1991). Critical thinking is not one single way of thinking, but rather a multidimensional thought process.

The literature review indicates the relevance of critical thinking for competence in nursing. Nurse educators have attempted to develop critical thinking abilities in students since the early 1930s. An historical analysis of nursing education concluded that the acquisitions of cultural knowledge, the possession of a strong science background, and the development of critical thinking skills are the goals of nursing education (Hanson, 1991). Critical thinking is still considered an important skill critical to the future of professional nursing practice.

Many studies agree that all nurses are required to synthesize multiple forms of knowledge to provide safe care to their patient (Kintgen-Andrews, 1991: Kramer, 1993; Tschikota, 1993). The lack of a universal definition has not prevented educators from regarding critical thinking as an essential educational component. There have been mixed results regarding the impact of nursing education on critical thinking. The literature reviewed describes studies that found critical thinking abilities to have no relationship to the level of competence and not to change significantly during the educational experience (Kintgen-Andrews, 1991; Maynard, 1991: Pless \& Clayton, 1993). However, other literature indicates nursing curricula do encourage critical thinking. Gross et al. (1987) evaluated the impact of the nursing curriculum on the student's ability to think critically. The sample consisted of 60 associate degree and 60 
baccalaureate degree students. The study suggests that 2 years of nursing education significantly improved critical thinking skills of both associate and baccalaureate students. Berger (1984) also found critical thinking scores on the Watson-Glaser critical thinking appraisal to increase significantly during a baccalaureate nursing program.

..- A substantial body of knowledge exists in the area of methods of teaching critical thinking (Bandman \& Bandman, 1988; Barnes, 1992; Bower \& McCarthy, 1993: deTornyay \& Thomas, 1987; Facione, 1986; MCMillian, 1987; Norris, 1989: Pond, Bradshaw \& Turner, 1991). These strategies include case studies, writing, computer assisted instruction, guided design, and the use of the nursing process. Students were found to need classroom learning experiences in critical thinking before entering the patient care setting (Pond et al., 1991).

Other studies attempted to determine if differences exist in critical thinking of different level students such as baccalaureate and associate nursing students (Lynch, 1988). The literature appears to support the position that graduates from different educational levels have different cognitive abilities. Brooks and Shepard (1990) found generic baccalaureate seniors to have a higher level of critical thinking ability than associate and diploma nursing seniors. The WatsonGlaser Critical Thinking Appraisal was used to analyze critical thinking abilities of the students. The statistical analysis using ANOVA indicated that the mean scores for the students in the baccalaureate program were significantly different from the associate and diploma mean scores. A stratified sample of nursing students also analyzed by the Watson-Glaser instrument was used by Pardue 
(1987). The result also suggests that the more educated the nurse, the greater the critical thinking ability.

The notion that critical thinking skills can be developed and should be fostered by curriculum is evident in many of the studies noted. McNeelyGreene's (1991) addresses the question of whether critical thinking is encouraged in associate degree programs. The purpose of McNeely-Greene's dissertation was to examine an associate degree nursing program to determine if critical thinking instruction existed in the first and fourth semesters of the curriculum. All course objectives, tests, and quiz items were assigned a level of Bloom's taxonomy. The oral and written assignments were assessed. The faculty members were interviewed to determine their beliefs and instructional straiegies regarding critical thinking. The results indicated that some faculty targeted critical thinking instruction. However, the trends indicated that the majority of their exam questions were in the knowledge category. Written and oral assignments were identified as instruction that encouraged critical thinking. These assignments only accounted for $26.7 \%$ of the course grade.

The idea to use Bloom's Taxonomy for this study originated with McNeelyGreene's work. Kemp (1985) also utilizes Bloom's taxonomy in his instructional design process. Objectives classified with Bloom's taxonomy are one of the four fundamental elements in this process. Kemp indicates that too often major attention is given in a course to the lowest cognitive level objectives. McNeelyGreene (1991) used Bloom's taxonomy with critical thinking to identify what type of objectives a nursing program chose. Her premise is that critical thinking is reflected in higher-order objectives. Paul (1985), however, finds Bloom's 
taxonomy to be a one-way hierarchy that one can not depend on to classify outcomes without the development of critical thinking skills on the part of the instructors.

Although critical thinking is considered paramount in education, the literature reviewed has mixed results on how to define and measure critical thinking. Critical thinking is a necessary skill for nursing students. More research is needed to identify ways to encourage critical thinking. This study attempts to add to this body of knowledge by identifying the frequency in which higher-level objectives and their evaluation are currently used in an associate degree nursing program, Kramer (1993) and Bloom (1956) provide the framework for this study. 


\section{Chapter 3}

\section{METHODOLOGY}

This study is a correctional design using ordinal data. This nonexperimental research design is congruent with the purpose of the study to see if there is a relationship between the variables. This study did not attempt to determine cause and effect, but to describe what is currently in practice.

The independent variable was the percentage of higher-order objectives, defined by Bloom's Taxonomy, used in an associate degree course. The dependent variable was the percentage of exam questions that related to the higher-order objectives. One exam from each course throughout an associate degree nursing program was selected. The objectives outlined for the selected exam were identified. Bloom's taxonomy was then used to categorize the objectives. The objectives found to be higher-level were then counted. Exam questions related to the higher-level objectives were then identified, tallied, and the percentage computed.

\section{Subjects and Data Collection}

A homogeneous sample and consistent data collection procedures were used as means of controlling extraneous variables. The target population was an associate degree nursing program in northern California. The Human Subjects-Institutional Review Board at San Jose State University approved this study on August 22, 1994 (See Appendix A). A convenience sample of one school was used. The community college nursing program used for this study offers 12 nursing courses a semester. Each nursing course is 6 weeks long, and four of these courses run simultaneously. Each course has an average of three 
multiple choice examinations. These examinations make up approximately $95 \%$ of the course grade. Students purchase a class syllabus at the beginning of each course which outlines the objectives of the course content and exams.

This associate degree nursing program is accredited by the National League for Nurses and the California Board of Registered Nurses. The program prepares the students to sit for the National Council Licensure Examination for Registered Nurses upon graduation. Students are eligible for enrollment for the generic nursing program with a grade point average above 2.0 and the completion of program prerequisites. Eligibility is also determined by placement test score or 15 units of college study. Acceptance into the program is by the lottery system. A grade of $C$ or better is required on all nursing courses and in anatomy, physiology, and microbiology.

The data for this study were collected by one researcher. One exam for each course was randomly selected by the researcher. All exams were selected from the Fall 1993 academic semester. The names of the course were withheld so the data would reflect the whole curriculum. The objectives for the exam chosen for each class was copied out of the course syllabi. The objectives were categorized using Bloom's taxonomy. A specification table relating subject content and objectives from a course to Bloom's taxonomy (Kemp, 1985) in the cognitive domain was used as the tool to categorize the objectives for each course.

A list of verbs that express behaviors on each of the six levels in Bloom's taxonomy assisted in recognizing the higher cognitive levels. This list was used to categorize the course objectives (Kemp, 1985). The number of higher-level 
objectives that were identified using this method was counted. The percentage of higher-level objectives was computed for each course. For this study, the objectives that fell into the application, analysis, synthesis, and evaluation categories were considered higher-level objectives. Once the higher-level objectives were identified, the exams were analyzed. Exam questions with content area relating to the higher-level objectives were identified and counted. The percentage of these exam questions was computed for each exam. Analysis Procedure

Spearman's rank correlation coefficient was used in this study to describe the relationship between the variables. No assumption of a normal distribution needs to be made with nonparametric data (Sprent, 1989). The data were compiled and analyzed in an attempt to answer the research question. Descriptive statistics were used to describe both variables, including the percentages of the independent and dependent variables.

The independent variable, percentage of higher-level objectives in a course, and the dependent variable, percentage of exam questions that related to the higher-level objectives, are examples of ordinal data (Kitchens, 1987). Due to the use of ordinal data and the lack of a normal distribution, Spearman's rank correlation was used to test the relationship between the two variables (Kitchens). Spearman's rank correlation coefficient is denoted by is (Kitchens, 1987; Sprent, 1989). Given the sample data, ranks were assigned to the independent and the dependent variables. The formula for is is the same as the formula for Pearson's correlation coefficient, I. except that Spearman's is applied to the ranks of nonparametric data (Kitchens, 1987; Sprent, 1989). 
The data for each variable in this study were ranked from 1, the smallest percentage observed, to 11 , the largest percentage observed. For example, the class with the least occurrence of higher-level objectives was ranked number 1, and the class found to have the largest occurrence of higher-level objectives was ranked number 11. Similarly, the exams with the occurrence of questions that relate to the higher-level objectives were ranked from 1 to 11 . Spearman's rank correlation was then calculated on the assigned ranks. Contingency tables and a bar graph was used to show the data falling in the various categories. In addition, descriptive statistics on the categories of objectives and exam questions were calculated. 


\section{Chapter 4}

\section{FINDINGS AND INTERPRETATION}

The purpose of this study was to gather data on an associate degree nursing program to determine if critical thinking was encouraged and evaluated by the use of higher-level objectives. This study attempted to answer the following research question: Is there a relationship between the percentage of higher-level educational objectives and the percentage of related examination questions in an associate degree nursing program? Eleven of the 12 courses in the nursing program were used for the data analysis. One class was not used because it did not use written examinations as a mean of testing. The first exam was analyzed from each course for this study. Using the first exam allowed for easy recognition of corresponding objectives in the class syllabus. The data gathered from the objectives and corresponding first exams included categorizing the objectives into one of the six levels of Bloom's cognitive domain and the number of test questions that referred to each objective.

The overall percentage of higher-level objectives for all the classes was $17 \%$. The overall percentage of test questions that referred to a higher level objective was $21 \%$. Overall, 566 objectives were analyzed. Ninety-seven objectives were found to be from the higher-level domains of application, analysis, synthesis, and evaluation (see Table 1). Three hundred and ninety $(68.9 \%)$ of the objectives were at the comprehension level of the taxonomy. Comprehension is considered a lower-level domain. The knowledge category was the next largest domain, containing $79(13.45 \%)$ of the objectives. These 
are also considered to be lower-level objectives. Table 1 shows the frequency and percentage of objectives in each domain.

Table 1

Objectives in the Cognitive Domain

\begin{tabular}{|l|c|c|}
\hline $\begin{array}{l}\text { Six levels of Cognitive } \\
\text { Domain }\end{array}$ & Frequency & Percentage \\
\hline Knowledge & 79 & $14.0 \%$ \\
\hline Comprehension & 390 & $68.9 \%$ \\
\hline Application & 12 & $2.1 \%$ \\
\hline Analysis & 76 & $13.4 \%$ \\
\hline Synthesis & 2 & $0.4 \%$ \\
\hline Evaluation & 7 & $1.2 \%$ \\
\hline
\end{tabular}

In an attempt to see if there were differences in the percentage of higher-level objectives as seniority increased, calculations were made by semester. Table 2 shows that the course in the second semester, for the first exam given, had the highest percentage of higher-level objectives. There was no apparent trend for more higher-level objectives during progression through the program.

The data were then analyzed using non-parametric statistics to test for a relationship between objectives and examination questions. Spearman's correlation coefficient of is $=.09$, was calculated after ranking the classes from highest occurrence of higher-level objectives to the lowest occurrence of higher-level objectives. Spearman's correlation coefficient of $\underline{s}=.38$ was found when the percentage data were used as ranking in the computation (see 


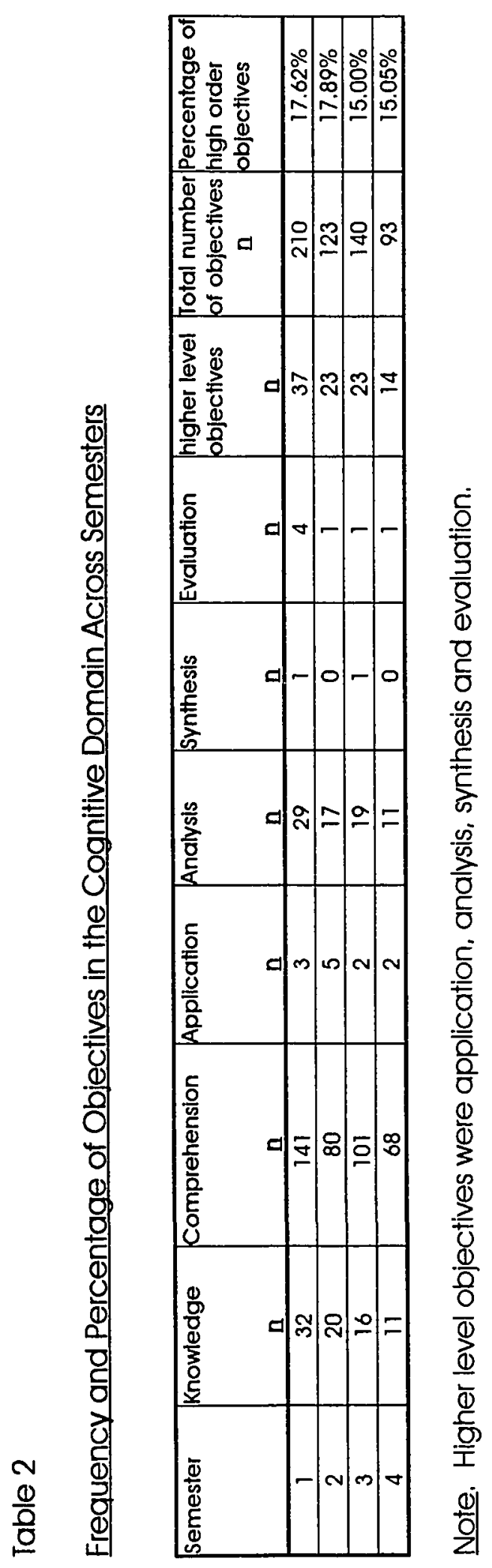


Appendix D). The alpha was set at ,05 for level of significance. Both findings indicate that there was not a statistically significant correlation between the occurrence of higher-level objectives and related exam questions in the ADN program evaluated since neither correlation coefficient reached .05 significance.

The lack of a statistically significant relationship suggests that variables other than the level of objectives must influence the content of the examinations. Figure 1 shows a bar graph of the percentage of higher-level objectives and the percentage of related examination questions per course.

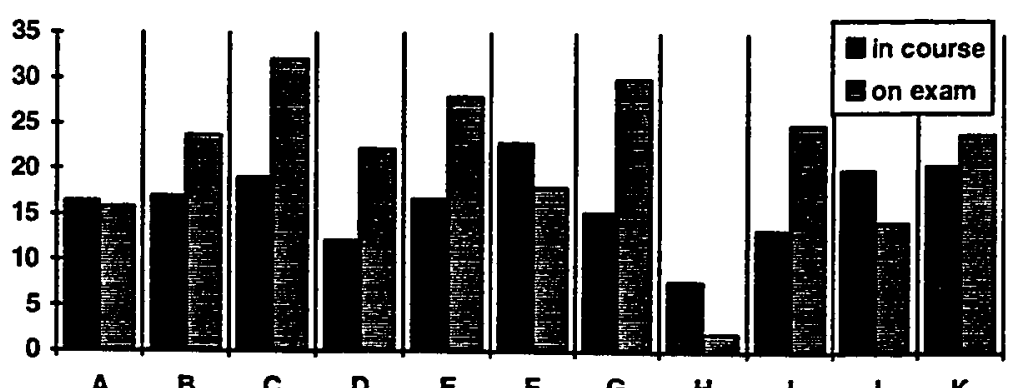

Eigure 1. Percentage of higher-level objectives and the percentage of related examination questions per course.

This research study has suggested that there was no statistical significance in the relationship between the percentage of higher-level objectives and the percentage of related exam questions in an associate degree nursing program. The occurrence of higher-level objectives did not increase in upper level courses. Five hundred and sixty-six objectives and 499 test questions 


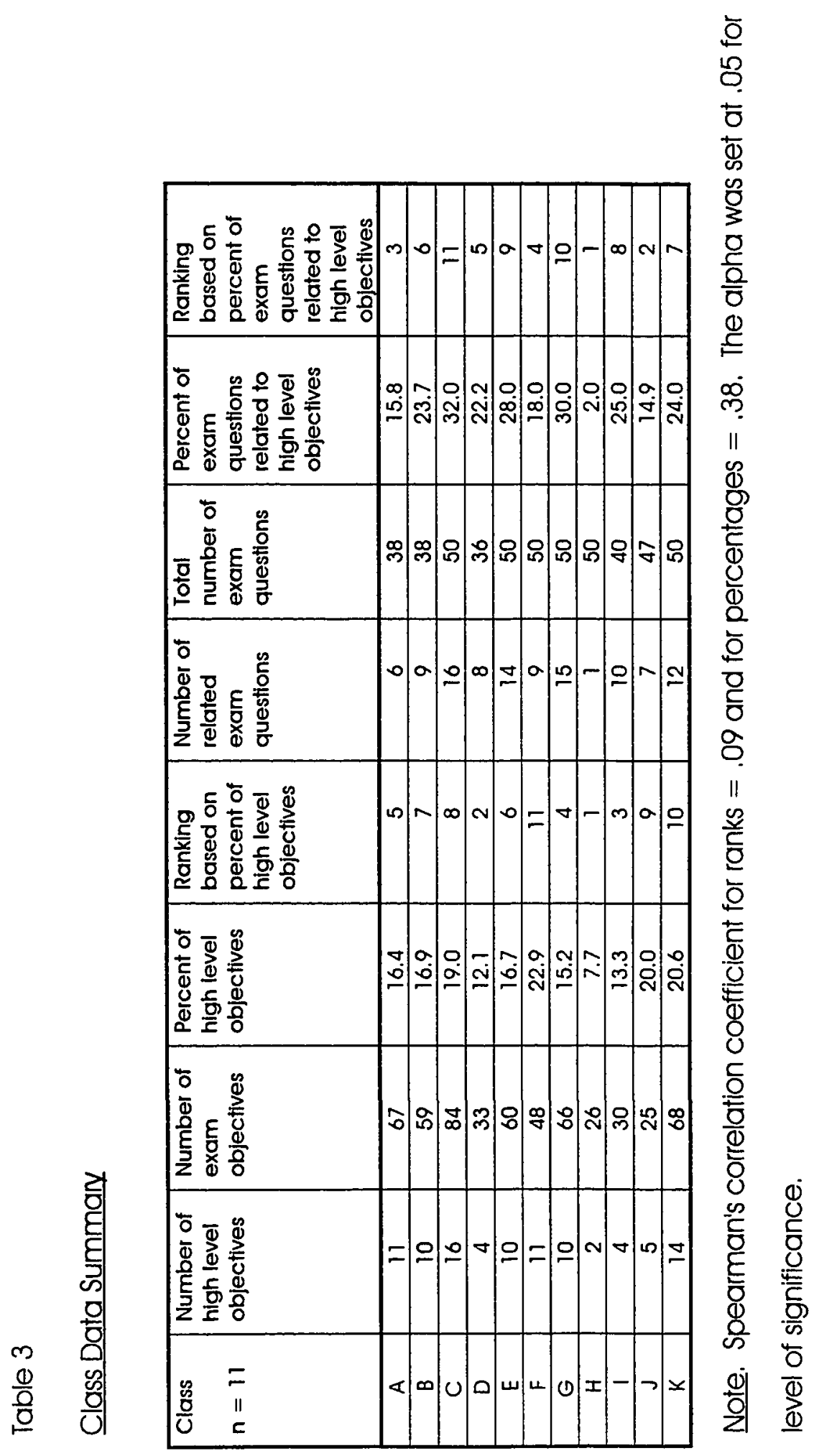


were analyzed. The highest percentage of objectives were found in the lowlevel comprehension domain (69\%). Only $97(18 \%)$ of the objectives were found to be of higher-level domains. The mean number of higher-level objectives used in a course was nine. The mean number of test questions that referred to a higher-level objective was 10. Table 3 summarizes the collected data. The percentage of course objectives were not statistically correlated with the percentage of course examination questions following the criteria of this study. 


\section{Chapter 5}

DISCUSSION

Critical thinking is considered an important skill in the future of professional nursing practice. Baccalaureate education is the only level of nursing education mandated to develop critical thinking in students. Nursing faculty at all levels have expressed concern over the apparent inability of some students to apply knowledge from course content to patient care situations. Facilitating the development of critical thinking can be accomplished by nursing instructors writing and evaluating higher-level objectives. These objectives would encourage the students to use critical thinking skills in meeting the objectives. Test questions should then assess the content from the objectives. With the increased technology in today's health care arena, nursing education at all levels should be required to encourage critical thinking.

Summary of the Study

The liferature review showed mixed results on the definition and measurement of critical thinking. Critical thinking is defined in this study by Kramer's (1993) definition "...critical thinking is generally regarded as a practical activity that helps the learner develop broad understanding of situations... the learner explores some situations, questions, or problem to reach a reasoned conclusion that can be convincingly justified" $(p, 406)$. The conceptual framework for this study was derived from the works of Kramer (1993) and Bloom (1956). The purpose of this study was to gather data on an associate degree nursing program to determine if critical thinking was encouraged and evaluated by use of higher-level objectives. 
Data were collected from course objectives and exams from an associate degree nursing program in northern California. The first exam from each course and the corresponding objectives were analyzed using Bloom's taxonomy. The action verb in each objective was used to identify the appropriate level of Bloom's six cognitive domains. A shopping list of verbs by Kemp (1975) along with Bloom's (1956) definitions of each level were the tools used to identify the data (See appendix B). Spearman's rank correlation was used to test the relationship between the variables. Descriptive statistics identified the percentage of the independent variable, which was the percentage of higher-level objectives, and the dependent variable, which was the percentage of related examination questions.

\section{Conclusions}

This study found that there was no statistical significance between the percentage of higher-level objectives and the percentage of related questions on examinations in an associate degree nursing program. Therefore there was no relationship found between the independent and dependent variables of the ADN program studied. MCNeely-Greene's findings (1991) appear similar to this study:

In no case, for any of the courses, does the percentage of objectives in each level of Bloom's taxonomy match the percentage of test...items on Bloom's taxonomy. In fact, there appears to be no relationship the course and the breakdown of quiz and test items on the taxonomy for the courses. (p. 100) 
The program used low-level objectives predominantly, and there did not appear to be a progression in higher-level objectives as the students advanced through the program. This finding was different then McNeely-Greene (1991) who did find an increase in higher-level objectives from the first compared to the fourth year of an ADN program.

These findings suggest that examinations are not tied to the level of objectives. This may indicate that the outcomes of the course, as indicated by the objectives, are not reflected in the assessments of the students by written examination. Examinations may reflect the topics covered in the class in approximately the same ratio as the amount of class time spent on the topic instead of the level of the objective. However, that was a variable that was not evaluated in this study. Also, written examinations may not be the only way instructors are assessing higher-level objectives. Furthermore, the data reflect one exam out of three exams for each course. The variables, although not statistically significantly related, were useful in the examination of this curriculum. If critical thinking is a goal of nursing faculty, then utilization of higher-level objectives with follow up assessment may need to be emphasized. The issue of how great a priority critical thinking has been given in this associate degree program may need to be addressed by the faculty.

There are no norms in the literature review to compare with these findings. Encouragement of critical thinking is important in nursing education. Nursing curricula should emphasize requiring and assessing higher-level objectives in each course. 


\section{Scope and Limitations}

The most significant limitation of this study was the narrow focus on one associate degree nursing program. Because this particular program was selected for convenience and due to the sample size, the findings could not be generalized to other programs or populations. The study examined only one a.umination and related objectives for each course. This was only a small portion of a larger curriculum. A random sampling of exams may have given a broader picture of the curriculum and affected the results. If other aspects of the curriculum were addressed, they might affect the results obtained in this study. In addition, only one researcher collected and categorized data according to her understanding of the tools used. This may bias the results due to the researcher's familiarity with the program. It is also acknowledged that no control was exerted over the nursing instructor's knowledge regarding writing objectives and examinations. Some instructors may have had different levels of knowledge regarding writing objectives and the application of critical thinking.

Recommendations

A number of further studies are recommended in relation to this research. Within this program, all tests and objectives currently in use could be analyzed using the same format as in this study, In addition, a correlational study between the progression of the nursing courses compared to the amount of higher-level objectives utilized could be attempted. Also, other associate degree programs could be evaluated to ascertain the norm for an associate degree program's use of higher-level objectives. From those data, nursing educators can estimate a minimum amount of higher-level objectives for each 
course. Bloom (1956) suggested the taxonomy could be used as a communication tool by schools to examine the similarities and differences among the goals of instructional programs. Further, the use of the taxonomy would aid in the clarification of a practical definition of critical thinking across the curriculum.

Another recommended study is a comparison of an ADN programs' use of higher-level objectives with that of baccalaureate programs. An analysis of actual instructional methods would also provide relevant information on the types of critical thinking instruction occurring in the program. A pre-test and post-test could be given in the program to assess growth of critical thinking skills in courses with various instructional methods.

Further studies on associate degree programs' utilization of critical thinking skills could give evidence to support the notion that all levels of nursing education should teach critical thinking. The baccalaureate level is currently the only level mandated to require critical thinking for accreditation. However, more nurses are graduating from associate degree nursing programs than baccalaureate programs (National League of Nursing Division of Research, 1993). With the increased technology in today's health care arena, nursing education at all levels should be required to encourage critical thinking. 
References 


\section{References}

Bandman, E.L. \& Bandman, B. (1988). Critical thinking in nursing. East Norwalk: Appleton \& Lange.

Barnes, C.A. (Ed.) (1992). Critical thinking educational imperative. San Francisco: Jossey Bass Publishers.

Berger, M.C. (1984). Clinical thinking ability and nursing students. Jeurnal of Nursing Education, 233 (7), 306-308.

Bloom, B.S. (Ed.), Engelhart, M.D., Furst, E.J., Hill, W.H. \& Kathwohl, D.R. (1956). Iaxonomy of educational objectives (vol. 1). New York: David Mckay.

Bowers, B., \& McCarthy, D. (1993). Developing analytic thinking skills in early undergraduate education. Journal of Nursing Education, 36 (3), 107-114.

Brooks, K.L. \& Shepard, J.M. (1990). The relationship between clinical decision making skills in nursing and general critical thinking abilities of senior nursing students in four types of nursing programs. Journal of Nursing Education, 29 (9), 391-399.

deTornyay, R. \& Thompson, M. (1987). Strategies for teaching nursing. New York: John Wiley \& Sons.

Facione, P.A. (1986). Testing college-level critical thinking. Liberal Education, 72 (3), 221-231.

Gross, Y., Takazawa, E. \& Rose, C. (1987). Critical thinking and nursing education. Journal of Nursing Education, 26 (8), 317-323. 
Hanson, K. (1991). An analysis of the historical context of liberal education in nursing education from 1924 to 1939. Journal of Professional Nursing, I (6), 341-350.

Jones, S.A. \& Brown, L.N. (1991). Critical thinking: Impact on nursing education. Jeurnal of Advanced Nursing, 16 (5), 529-533.

Kemp. J. (1985). The instructional design process. New York: Harper \& Row. Kitchen, L.T. (1987). Exploring satistics a modern introduction. St. Paul: West Publishing.

Kintgen-Andrews, J. (1991). Critical thinking and nursing education: Perplexities and insights, Journal of Nursing Education, 30 (4), 152-157.

Kramer, M. (1993). Concepts clarification and critical thinking: Integrated processes, Journal of Nursing Education, 32, 406-414.

Le Francois, G. (1994). Psychology for teaching. CA: Wadsworth.

Lynch, M. (1988), Critical thinking: A comparative study of baccalaureate and associate degree nursing students. Unpublished doctoral dissertation, George Peabody College for teachers of Vanderbilt University.

Maynard, C. (1991). The relationship of critical thinking ability, stage of skill acquisition, vears of practice, and organizational context to professional nursing. Doctoral dissertation, University of Minnesota.

McMillan. J.H. (1987). Enhancing college students' critical thinking: A review of studies. Research in Higher Education, 26 (1), 3-29.

McNeely-Greene, D.E. (1991). Critical thinking instruction in an associate degree nursing curriculum (Doctoral dissertation, University of Delaware). MD.: U.M.I. 
Miller, M. \& Malcolm, N. (1990). Critical thinking in the curriculum. Nursing and Health Care, 11 (2), 67-73.

National League for Nursing. (1993). Crieria and guidelines for the ealuation of associate degee programs in nursinng (pub. no. 23-2439). New York: Author.

National League for Nursing. (1992). Criteria and quidelines for the evaluation of baccalaureate and higher degre programs in nursing (pub. no. 15-2474). New York: Author.

National Legue of Nursing Division of Research. (1993). Nursing data source 1993 (vol.1). New york: Author.

Norris, S.P. (1989). Can we test validity for critical thinking? Educational Researcher, 18 (9), 21-26.

Pardue, S.F. (1987). Decision making skills and critical thinking ability among associate degree, diploma, baccalaureate, and master's prepared nurses. Journal of Nursing Education, 26, 354-361.

Paul, R.W. (1985). Bloom's taxonomy and critical thinking instruction. Educational Legdership, 4l, 36-39.

Pless, B. \& Clayton, G. (1993). Clarifying the concepts of critical thinking in nursing. Journal of Nursing Education, 32 (9), 425-428.

Pond, E. F., Bradshaw,M.J. \& Turner,S.L. (1991), Teaching strategies for critical thinking. Nurse Educator, 16 (6), 18-22.

Siegel, H. (1980). Critical thinking as an educational ideal. The eduacational forum, 45, 7-23. 
Sprent, P. (1989). Applied Nonparametric Statistical Methods, London:Chapman and Hall.

Tschikota, S. (1993). The clinical decision making process of student nurses. Journal of Nursing Education, 32 (9), 389-398.

White, N., Beardslee, N., Peters, D. \& Supplies,J. (1990). Promoting critical thinking skills, Nurse Educator, 15 (5), 16-19.

Yinger, R. (1980). Fostering critical thinking: New directions for teaching and learning. San Francisco: Jossey-Bass. 
Appendix A

Human Subjects Approval 
Office of the Academic Vice President - Assoclate Academic Vice President • Graduate Studles and Rerearch

One Washington Square • San José, California 95192-0025 • 408/924-2480

TO: $\quad$ Susan M. Wetzel

32455 Lois Wy.

Union City, CA 94587

FROM: Serena w. Stanford, Ph.D. Serenc H. Htanfore
AAVP, Graduate Studies and Research

DATE: $\quad \cdots$ August 22, 1994

The Human Subjects-Institutional Review Board has approved your request to use human subjects in the study entitled:

"The Relationship of Higher-level objectives and the Frequency of Related Exam Questions in an ADN Program"

This approval is contingent upon the subjects participating in your research project being appropriately protected from risk. This includes the protection of the anonymity of the subjects' identity when they participate in your research projects, and with regard to any and all data that may be collected from the subjects. $T$ h $e$ Board's approval includes continued monitoring of your research by the Board to assure that the subjects are being adequately and properly protected from such risks. If at any time a subject becomes injured or complains of injury, you must notify Dr. Serena stanford immediately. Injury includes but is not limited to bodily harm, psychological trauma and relaese of potentially damaging personal information.

Please also be advised that each subject needs to be fully informed and aware that their participation in your research projects is voluntary, and that he or she may withdraw from the project at anytime. Further, a subject's participation, refusal to participate or withdrawal will not affect any services the subject is receiving or will receive at the institution in which the research is being conducted. If you have questions, please contact me at (408) 924-2480. 
Appendix B

Shopping List of Verbs 


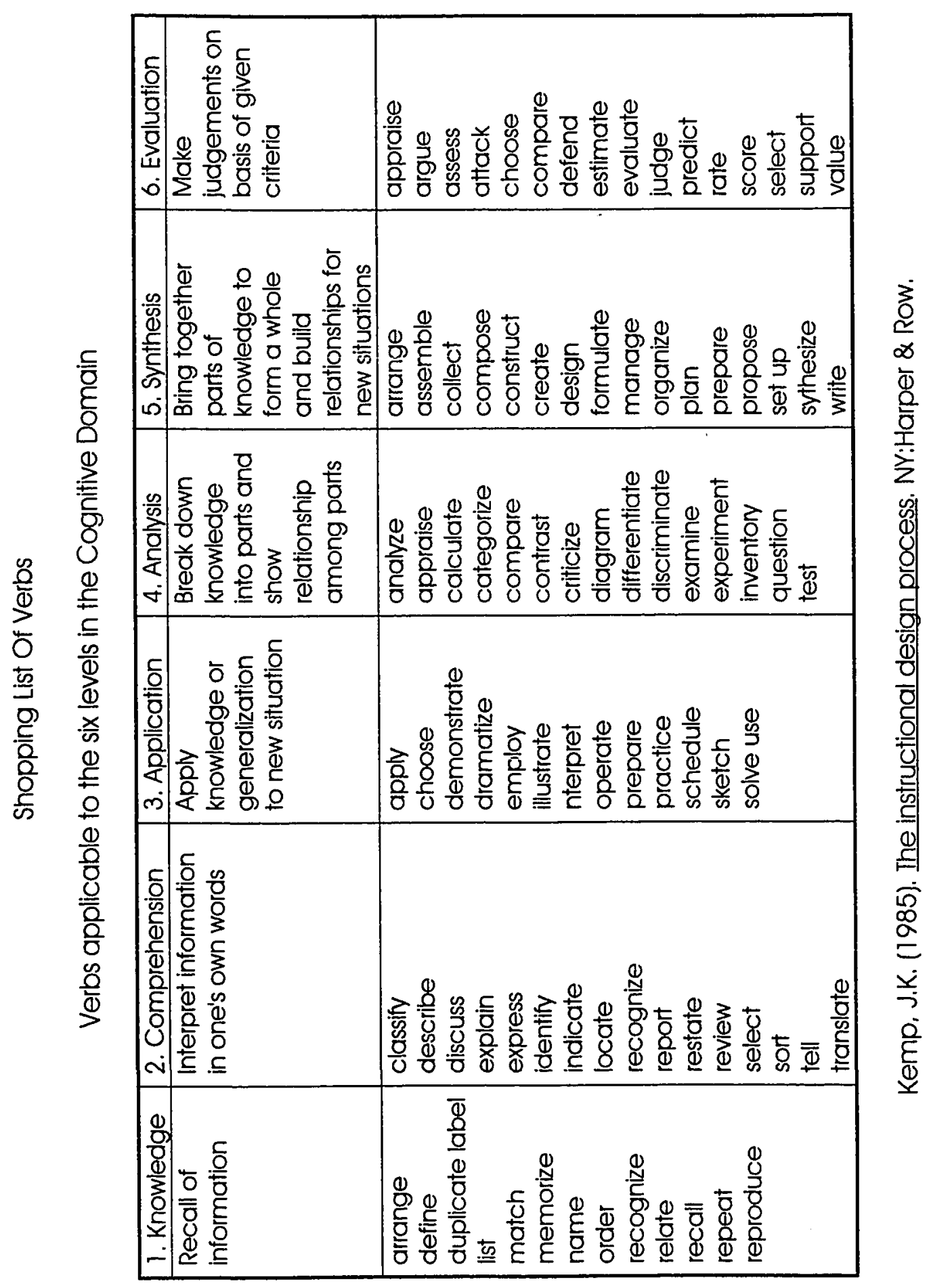


Appendix C

Spearman's Correlation Coefficient 
Ranking

\begin{tabular}{|r|r|r|r|r|r|}
\cline { 2 - 6 } \multicolumn{1}{c|}{} & \multicolumn{1}{c|}{$x$} & \multicolumn{1}{c|}{$y$} & \multicolumn{1}{c|}{$x 2$} & \multicolumn{1}{c|}{$y 2$} & \multicolumn{1}{c|}{$x y$} \\
\hline 1 & 5.00 & 3.00 & 25.00 & 9.00 & 15.00 \\
\hline 2 & 7.00 & 6.00 & 49.00 & 36.00 & 42.00 \\
\hline 3 & 8.00 & 11.00 & 64.00 & 121.00 & 88.00 \\
\hline 4 & 2.00 & 5.00 & 4.00 & 25.00 & 10.00 \\
\hline 5 & 6.00 & 9.00 & 36.00 & 81.00 & 54.00 \\
\hline 6 & 11.00 & 4.00 & 121.00 & 16.00 & 44.00 \\
\hline 7 & 4.00 & 10.00 & 16.00 & 100.00 & 40.00 \\
\hline 8 & 1.00 & 1.00 & 1.00 & 1.00 & 1.00 \\
\hline 9 & 3.00 & 8.00 & 9.00 & 64.00 & 24.00 \\
\hline 10 & 9.00 & 2.00 & 81.00 & 4.00 & 18.00 \\
\hline 11 & 10.00 & 7.00 & 100.00 & 49.00 & 70.00 \\
\hline & 66.00 & 66.00 & 506.00 & 506.00 & 406.00 \\
\hline
\end{tabular}

$S S x y=406-(66)(66) / 11=10$

$S S x x=506-(66)(66) / 11=110$

$\mathrm{SS} y=506-(66)(66) / 11=110$

$r_{S}=10 /((110)(110))^{1 / 2}=0.09$

Level of Significance $=0.05$

Degree of Freedom N-2 =9 
Percentages

\begin{tabular}{|r|r|r|r|r|r|}
\cline { 2 - 6 } \multicolumn{1}{c|}{} & \multicolumn{1}{c|}{$x$} & \multicolumn{1}{c|}{$y$} & \multicolumn{1}{c|}{$x 2$} & \multicolumn{1}{c|}{$y 2$} & \multicolumn{1}{c|}{$x y$} \\
\hline 1 & 16.42 & 15.79 & 269.55 & 249.31 & 259.23 \\
\hline 2 & 16.95 & 23.68 & 287.27 & 560.94 & 401.43 \\
\hline 3 & 19.05 & 32.00 & 362.81 & 1024.00 & 609.52 \\
\hline 4 & 12.12 & 22.22 & 146.92 & 493.83 & 269.36 \\
\hline 5 & 16.67 & 28.00 & 277.78 & 784.00 & 466.67 \\
\hline 6 & 22.92 & 18.00 & 525.17 & 324.00 & 412.50 \\
\hline 7 & 15.15 & 30.00 & 229.57 & 900.00 & 454.55 \\
\hline 8 & 7.69 & 2.00 & 59.17 & 4.00 & 15.38 \\
\hline 9 & 13.33 & 25.00 & 177.78 & 625.00 & 333.33 \\
\hline 10 & 20.00 & 14.89 & 400.00 & 221.82 & 297.87 \\
\hline 11 & 20.59 & 24.00 & 423.88 & 576.00 & 494.12 \\
\hline & 180.88 & 235.59 & 3159.90 & 5762.90 & 4013.96 \\
\hline
\end{tabular}

SSxy $=4013.96-(180.88)(235.59) / 11=140.00$

SSXX $=3159.90-(180.88)(180.88) / 11=185.58$

$S S W=5762.90-(235.59)(235.59) / 11=717.20$

is $=140.00 /((185.58)(717.20))^{1 / 2}=0.38$

Level of Significance $=0.05$

Degree of Freedom N-2 $=9$ 